\title{
FACTORS AFFECTING POPULATION COMPOSITION AND SOCIAL ORGANIZATION OF WILD UNGULATES IN THE CHITWAN NATIONAL PARK, NEPAL
}

\section{Bishnu Prasad Bhattarai and Pavel Kindlmann}

Journal of Institute of Science and Technology

Volume 22, Issue 2, January 2018

ISSN: 2469-9062 (print), 2467-9240 (e)

Editors:

Prof. Dr. Kumar Sapkota

Prof. Dr. Armila Rajbhandari

Assoc. Prof. Dr. Gopi Chandra Kaphle Mrs. Reshma Tuladhar

JIST, 22 (2): 156-167 (2018)

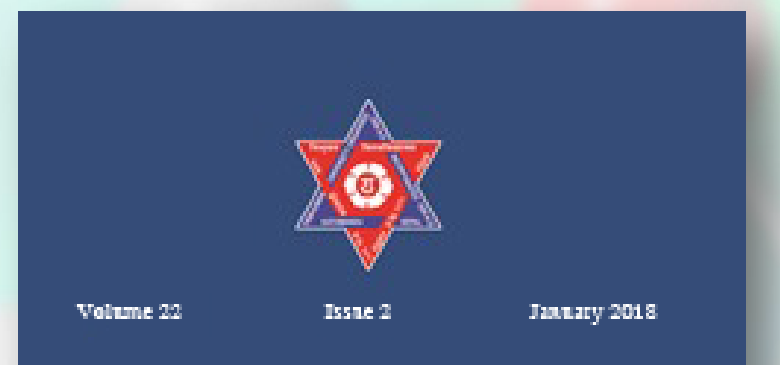

JOURNAL OF INSTITUTE OF SCIENCE AND TECHNOLOGY

Published by:

Institute of Science and Technology

Tribhuvan University

Kirtipur, Kathmandu, Nepal 


\title{
FACTORS AFFECTING POPULATION COMPOSITION AND SOCIAL ORGANIZATION OF WILD UNGULATES IN THE CHITWAN NATIONAL PARK, NEPAL
}

\author{
Bishnu Prasad Bhattarai ${ }^{1,3, *}$ and Pavel Kindlmann ${ }^{2}$ \\ ${ }^{1}$ Central Department of Zoology, Tribhuvan University, Kirtipur, Kathmandu, Nepal \\ ${ }^{2}$ Department of Biodiversity Research, Global Change Research Institute AS CR, \\ Bèlidla 986/4a, 60300 Brno, Czech Republic \\ ${ }^{3}$ Himalayan Environment and Public Health Network (HEPHN), Bharatpur, Nepal \\ *Corresponding E-mail: bpbhattarai@cdztu.edu.np
}

Received: 22 July, 2017; Revised: 1 November, 2017; Accepted: 2 November, 2017

\begin{abstract}
We investigated the factors affecting group sizes and population composition of chital (Axis axis), sambar (Rusa unicolor), hog deer (Axis porcinus), northern red muntjac (Muntiacus vaginalis), wild boar (Sus scrofa) and gaur (Bos gaurus) in the Chitwan National Park in southern Nepal. The study revealed that mean group sizes were the largest for chital (winter: 13.76 and summer: 11.01), followed by wild boar (winter: 6.89 and summer: 8.51), hog deer (winter: 5.52 and summer: 6.66), gaur (winter: 4.36 and summer: 5.81), sambar (winter: 1.86 and summer: 2.45) and muntjac (winter: 1.44 and summer: 1.46). The age and sex ratio of ungulates were biased towards females in all species. This study found the highest proportion of young individuals in wild boar and the lowest in gaur. Habitat structure, presence of predators and human disturbances strongly affected group size of ungulates in this area. Larger groups of ungulates were found in less disturbed open areas with high predatory pressure, while smaller groups and solitary individuals were found in highly disturbed forest areas. We recommend that management of human disturbances inside the park and regular monitoring of the changes in the demography of ungulate populations will improve longterm conservation strategies in this park.
\end{abstract}

Keywords: Ungulates, Predators, Population structure, Gregarious, Conservation, Disturbance.

\section{INTRODUCTION}

Enhancing and monitoring ungulate populations, which serve as prey for the endangered tiger is perhaps the most important task that wildlife managers are facing all across Asia (Karanth \& Stith, 1999). Effective monitoring of the populations and conservation planning of wild animals need detailed information on behavioral and demographic aspects (Caughley, 1977; Khan et al., 1995). These are influenced by body size, metabolic requirements, food habits, home range, mating system, and quality and abundance of forage in their territories (Geraldeau, 1988; Fritz \& de Garine-Wichatitsky, 1996), as well as by season. Availability of foraging grounds such as short grasslands and forest with thick understory vegetation are important predictors of ungulate abundance (Johnsingh \& Sankar, 1991). Although browse (young shoots of shrubs and trees) contains higher nutrition than grasses, browse is more scattered among widely dispersed individual plants in the forests than the mass of grasses clumped in the grasslands. Browse is therefore preferred by solitary ungulates and their small groups (Fritz \& de Garine-Wichatitsky, 1996) as it optimizes the net return for members of the herd (Geraldeau, 1988). Therefore, larger groups of ungulates are found mainly in grasslands, while solitary and very small groups are found in the forests.

Generally, the small-bodied muntjac (Muntiacus vaginalis), having high metabolic requirements, is known to be a browser and may forage in open scrubland but mainly inhabits forest land (Prater 1971) in small groups. Sambar (Rusa unicolor), a large-bodied browser (Johnsingh \& Sankar, 1991) inhabits forested areas, where forage is patchily 
distributed, so they are expected to occur in smallsized groups. The medium-sized chital is a mixedfeeder (Johnsingh \& Sankar, 1991) and inhabits both forested as well as open areas. Forest's edges are known to facilitate group formation in this species (Barrette, 1991), and they are expected to occur in larger groups than other ungulates.

Population structure in ungulates is usually biased towards females, which is attributed to sexual selection (Clutton-Brock et al., 1982). Among the deer (chital, sambar, hog deer and muntjac), males carry antlers, which are periodically shed, gaur shows a great degree of sexual dimorphism with males being considerably larger than females, while in the case of wild boar males have larger and more elaborate tusks than females.

Here, we studied the social organization and population structure of chital, sambar deer, hog deer, northern red muntjac, wild boar and gaur as well as the factors that influence the variations in the social organization and population structure of these ungulates in the Chitwan National Park (CNP). While the earlier studies (Schaller, 1967; Eisenberg \& Seidensticker, 1976; Seidensticker, 1976; Leuthold, 1977; Dinerstein, 1980; CluttonBrock et al., 1982; Mishra, 1982; Underwood, 1982; Geraldeau, 1988; Dhungel \& O'Gara, 1991; Karanth \& Sunquist, 1992; Khan et al., 1996; Fritz \& de Garine-Wichatitsky, 1996; Bagchi et al., 2004) were mostly devoted to the estimation of ungulate density and biomass in the Indian subcontinent, here we studied how the population structure of the species is affected by principal environmental factors, such as habitat structure, predation and human disturbances.

\section{MATERIALS AND METHODS}

\section{Study area}

Chitwan National Park (CNP $952.63 \mathrm{~km}^{2}$ ), located in the lowland terai region of Nepal, belongs to the UNESCO World Heritage Sites and high-priority tiger conservation units. Vegetation in the area can be characterized as subtropical moist deciduous forest with tall grassland (Stainton, 1972). It consists of diverse ecosystems, ranging from early successional alluvial floodplains along the rivers and their feeder streams up to the climax sal (Shorea robusta) forests on the foothills and slopes of the Churia range (Gurung, 1983; Dobremez 1976). Sal forest covers over $70 \%$, while savannatype grassland (both tall and short grasslands and riparian flood plains) covers $20 \%$ of the park area (Wikramanayake et al., 1998; Bhattarai \& Kindlmann, 2012). Other important habitats in the park include successional riverine forests, stretched along the rivers and Khair-sissoo forests covering old riverbeds of the Narayani and Rapti rivers (Gurung, 1983). Natural and physical forces such as floods, fires, erosion, soil aridity, grass cutting, and grazing by livestock contribute to a continually changing mosaic of grasslands as well as mixed deciduous and riverine forests in various stages of succession in the terai. In the lowlands, wildlife habitats are interspersed in a mosaic of large settlements and intensive cultivation.

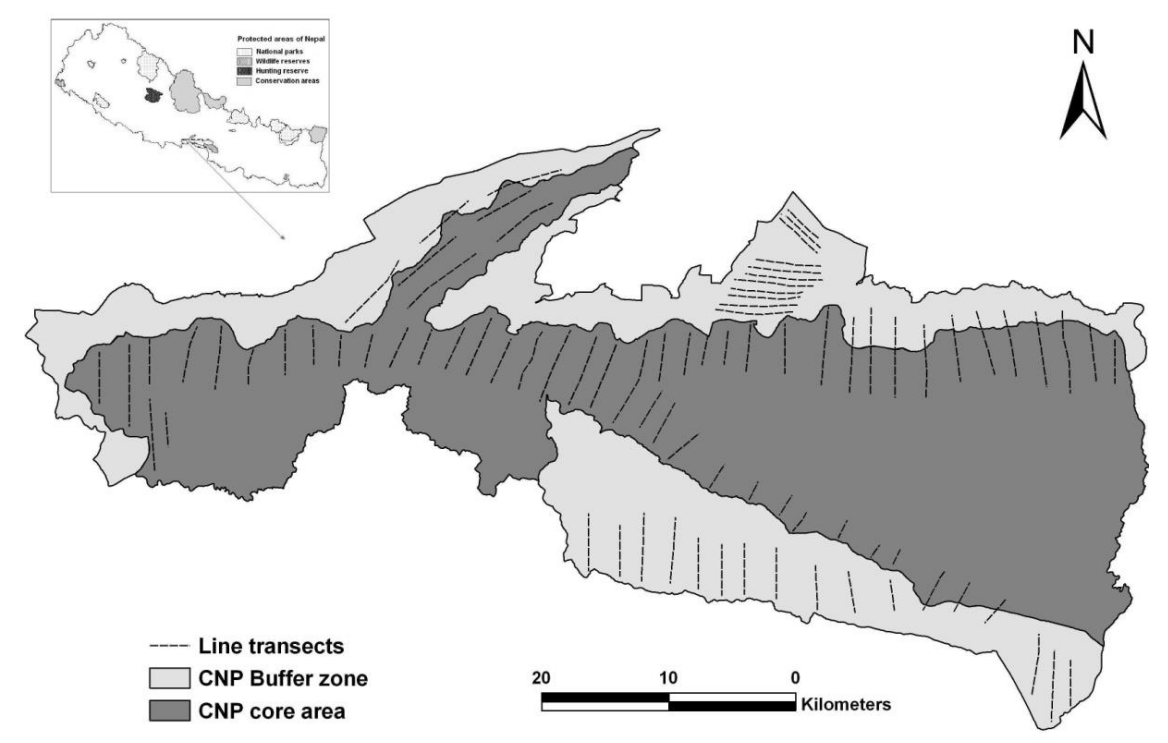

Fig. 1. Study area (CNP-Chitwan National Park) and location of the line transects sampling sites. 
Chitwan National Park hosts at least 70 species of mammals, including the prominent species like tiger (Panthera tigris), sloth bear (Melursus ursinus), greater one-horned rhinoceros (Rhinoceros unicornis), and Asian elephant (Elephas maximus) (CNP 2017). It also supports a high diversity of ungulates (Seidensticker, 1976; Stoen \& Wegge, 1996), including major tiger prey species such as gaur (Bos gaurus), sambar, chital (Axis axis), hog deer (Axis porcinus), northern red muntjac (Muntiacus vaginalis), wild boar (Sus scrofa), and two species of primates: terai gray langur (Semnopithecus hector) and rhesus macaque (Macaca mulatta) (Seidensticker, 1976; Dinerstein, 1980; Mishra, 1982; Smith, 1984; Dhungel \& O'Gara, 1991; Stoen \& Wegge, 1996; Smith et al. 1999; Bhattarai, 2003; Bhattarai \& Kindlmann 2012). The populations of large mammals, including tigers and rhinoceros in the Chitwan NP constitute significant portion of the global population of these species. Hence, Chitwan NP is listed among the 200 globally important areas of biodiversity (Wikramanayake et al., 2002).

\section{Methods}

Distance sampling was used to determine the social organization and population structure of wild ungulates and factors affecting them in the study area during winter (November, December, January and February) and summer (April, May, June and July) seasons of 2013. This method is practical, efficient and inexpensive (Buckland et al., 2004). We walked two times altogether 84 transects that covered a total of $1176 \mathrm{~km}$ (Figure 1). The location and the length of transects were defined by the accessibility on foot. The data were collected by walking during morning and day time to see the change in group size during morning and daytime. Survey in mid day hot time was avoided as the movement of animals was less. During walking on transects, we identified and recorded the species type, group size, age-sex and the environmental and disturbance factors.

A group of the ungulates was defined as a cluster of animals maximally $30 \mathrm{~m}$ from each other, showing a coordinated movement. These groups were later classified into six categories based on the number of individuals in a group: solitary (single individual), very small (2-5 individuals), small (610 individuals), medium (11-20 individuals), large (21-40 individuals), very large ( $>40$ individuals). The range of the group size classification in our study is more detailed than in previous studies of Karanth and Sunquist (1992) and Jarman (1974).
We also classified all the animals into the following demographic groups: adult males, adult females, subadults (yearlings 1-2 years in age) and young (newborn to 1 year in age) to estimate their age-sex ratio and to define the contribution of the proportions of age and sex of ungulates for the formation of the different sizes of the groups. We did not make any attempt to classify subadults and young according to sex and the animals that could not be classified were excluded for further analysis.

Besides these demographic parameters, we also collected the environmental and disturbance factors as the predictor variables that could have a crucial role in defining the group size and composition of these social ungulates. These factors include habitats (open, closed), topography (plains and gentle slope), distance to waterhole, presence of predator (tiger and leopard) and human disturbance index (presence of local people and livestock), two seasons (winter and summer) and time (morning and day) in the CNP. The presence signs of people were enumerated by recording the numbers of lopped trees, logged trees, grass cutting sites and the presence signs of livestock were enumerated by recording the feces of livestock. Firstly, the numbers of lopped trees, logged trees, grass cutting sites and faeces of livestock were scored 1, 2, 3, 4 or 5 for very low, low, moderate, high or very high disturbance, respectively. The sum of these scores represented a HDI for each sampling point.

The mean group size and the range of group size of ungulates were estimated with the aid of the total number of groups encountered during the study. Here, the mean group size represents the number of individuals likely to be encountered in an average group, and the range of group size is the range that has the highest and lowest number of individuals. The mean group size was calculated for two seasons in order to see the influence of the seasons in the group size. We used generalized linear model (GLM) to see the key factors that determine the grouping patterns of these ungulates. The factors were habitat (open, closed), topography (plains and gentle slope), distance to waterhole, presence of predator (presence and absence of tiger and leopard), human disturbance index (HDI), two seasons (winter and summer) and time (morning and day).

\section{RESULTS}

\section{Social organization}

We observed 319 groups of chital, 86 of sambar, 53 of hog deer, 137 of muntjac, 93 of wild boar and 32 groups of gaur during the transect walks. The mean 
and range of observed group size were largest for chital, followed by wild boar, hog deer, gaur, sambar deer and muntjac. Solitary individuals were most common in muntjac $(59.12 \%)$ and least in chital $(12.54 \%)$. Very small groups were most common in sambar deer, small groups in gaur, medium, large and very large groups were most common in chital (Table 1). Mean group size of all species, except of chital, was higher during summer season (Table 2). We tested the differences in the proportions of different group classes of each species by z-test (at 95\% confidence level) and found that there were significant differences in the proportions of the group sizes of chital $(z=4.02, p$ $=<0.0001)$, hog deer $(z=2.99, p=0.003)$, wild boar $(z=3.06, p=0.002)$ and gaur $(z=2.55, p=$ 0.01 ) while there were not significant differences in the proportions of the group sizes muntjac $(z=$ $1.54, p=0.123)$ and sambar deer $(z=1.39, p=$ $0.164)$.

Table 1: Total number of groups classified, range of observed group size and grouping tendencies of six wild ungulates in the CNP.

\begin{tabular}{|l|l|l|l|l|l|l|l|l|l|}
\hline \multirow{2}{*}{$\begin{array}{c}\text { Animal } \\
\text { type }\end{array}$} & \multirow{2}{*}{$\begin{array}{c}\text { Total number } \\
\text { of groups }\end{array}$} & \multirow{2}{*}{ Mean $\pm \mathbf{S E}^{*}$} & \multirow{2}{*}{$\begin{array}{c}\text { Range of observed } \\
\text { group size }\end{array}$} & \multicolumn{6}{|c|}{ Group size (\%) } \\
\cline { 5 - 11 } & & & $\mathbf{1}$ & $\mathbf{2 - 5}$ & $\mathbf{6 - 1 0}$ & $\mathbf{1 1 - 2 0}$ & $\mathbf{2 1 - \mathbf { 4 0 }}$ & $>\mathbf{4 1}$ \\
\hline Chital & 319 & $11.98 \pm 0.59$ & $1-56$ & 12.54 & 21.63 & 15.67 & 33.23 & 14.11 & 2.82 \\
\hline Sambar & 86 & $2.21 \pm 0.11$ & $1-5$ & 27.91 & 72.09 & 0.00 & 0.00 & 0.00 & 0.00 \\
\hline Hog deer & 53 & $6.21 \pm 0.60$ & $1-17$ & 22.64 & 32.08 & 26.42 & 18.87 & 0.00 & 0.00 \\
\hline Muntjac & 137 & $1.47 \pm 0.05$ & $1-3$ & 59.12 & 40.88 & 0.00 & 0.00 & 0.00 & 0.00 \\
\hline Wild boar & 93 & $7.87 \pm 0.56$ & $1-23$ & 15.05 & 22.58 & 29.03 & 31.18 & 2.15 & 0.00 \\
\hline Gaur & 32 & $5.31 \pm 0.61$ & $1-12$ & 21.88 & 37.50 & 31.25 & 9.38 & 0.00 & 0.00 \\
\hline
\end{tabular}

*SE is estimated standard error of group size.

Table 2: Seasonal variation in the group size of wild ungulates in the CNP.

\begin{tabular}{|l|l|l|}
\hline \multirow{2}{*}{ Animal type } & \multicolumn{2}{c|}{ Mean group size \pm SE* $^{*}$} \\
\cline { 2 - 3 } & \multicolumn{1}{c|}{ summer } & \multicolumn{1}{c|}{ winter } \\
\hline Chital & $11.01 \pm 0.67$ & $13.76 \pm 1.13$ \\
\hline Sambar & $2.45 \pm 0.15$ & $1.86 \pm 0.15$ \\
\hline Hog deer & $6.66 \pm 0.85$ & $5.52 \pm 0.80$ \\
\hline Muntjac & $1.46 \pm 1.22$ & $1.44 \pm 2.03$ \\
\hline Wild boar & $8.51 \pm 0.74$ & $6.89 \pm 0.83$ \\
\hline Gaur & $5.81 \pm 0.82$ & $4.36 \pm 0.81$ \\
\hline
\end{tabular}

*SE is estimated standard error of group size.

\section{Factors affecting the social organization}

Generalized linear model (Table 3) shows that the grouping patterns of the ungulate species studied were significantly affected by open habitats, presence of predators, summer season, morning time and human disturbance index. In these models, the positive values meant the preference, and negative values meant the avoidance of respective variables. For example, in the case of solitary chital (Table 3), we have the following model: $\left\{\begin{array}{llllll}1.54 & (0.50) & \text { Int }+0.024 & \text { (0.002) } & D W-2.02 & (0.46)\end{array}\right.$ $P P\}$, it means preference of DW (distance to waterhole) and avoidance of PP (predator presence). The group sizes of ungulates were not affected by the distance to waterhole, but the detection probability of the ungulates calculated in DISTANCE program by considering distance to waterhole as the perpendicular sighting distance between the center of the cluster of animals to the nearest waterhole (Buckland et al. 2004), strongly decreased with increasing distance to waterhole (figure 2. $\chi^{2}=103.56, p=<0.0001$ ).

Large and very large groups of chital significantly $(p=0.002)$ preferred open habitats (e.g., grasslands). Solitary and very small groups of chital significantly $(p<0.0001)$ avoided predators while large and very large groups occurred significantly more in presence of predators. Also, large groups significantly preferred plain areas. The distance to waterhole was not associated with group size of chital. Medium and large groups of chital significantly avoided the areas disturbed by humans. Likewise, small groups occurred significantly $(p<0.05)$ more in the summer season and medium groups less so (Table 3 ). 


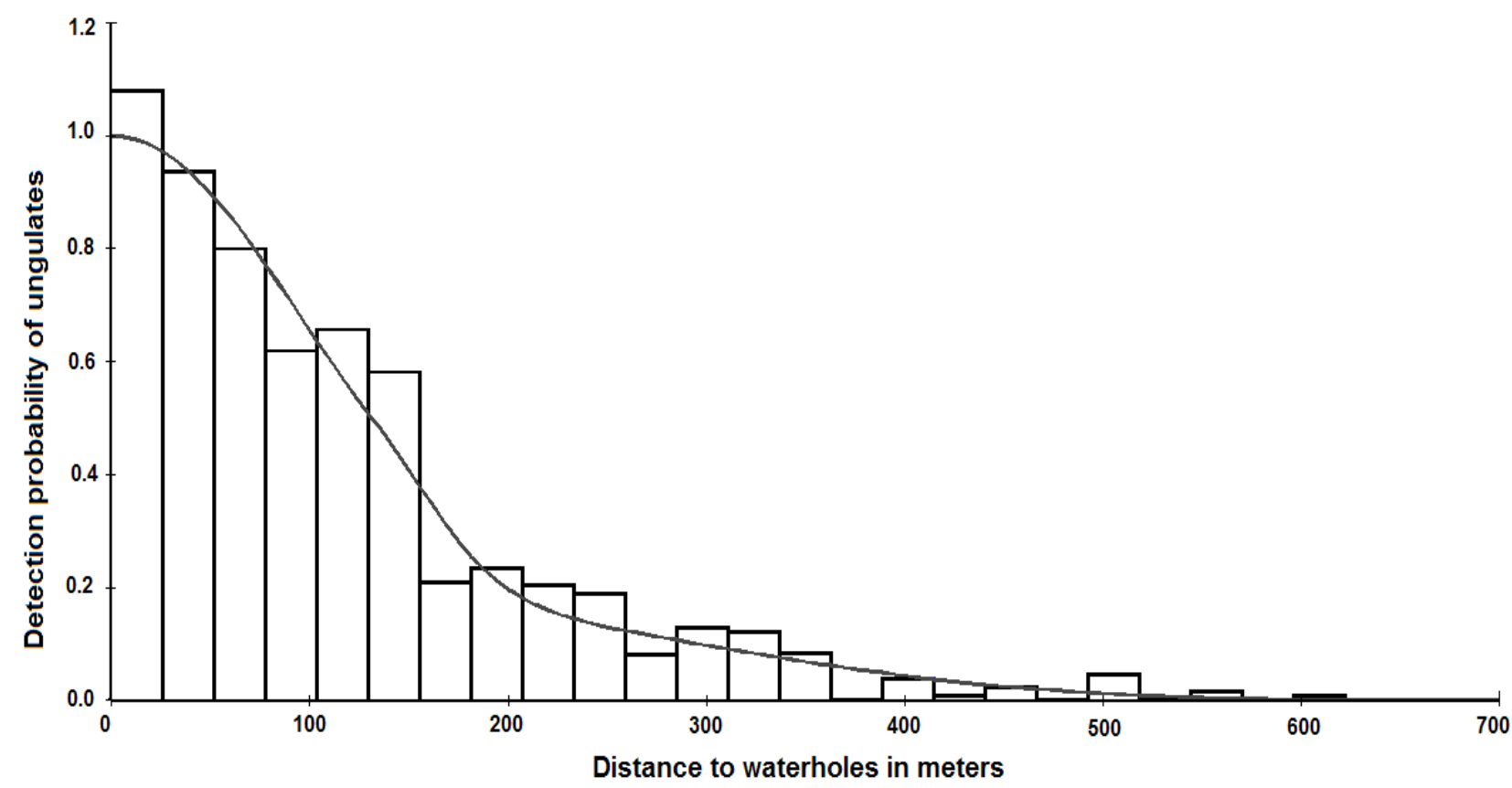

Fig. 2. Detection probability of ungulates from the waterhole distance measured by the distance of the center of the clusters of animal to the nearest waterhole.

Solitary individuals of sambar significantly avoided open habitats, presence of predators, summer season and human disturbances $(p<0.05)$. Similarly, very small groups occurred significantly more in open habitats, in presence of predators, in summer season and significantly avoided the human disturbances (Table 3). Solitary individuals, as well as small and medium groups of hog deer preferred the open habitats while the very small groups avoided open habitats (Table 3).

In case of muntjac, solitary individuals significantly preferred open habitats $(\mathrm{p}<0.05)$ during morning time $(p<0.001)$ and significantly avoided places with presence of predators $(p<0.05)$ while very small groups significantly avoided open habitats during morning time but occurred significantly more often in the presence of predators (Table 3 ).

Our model did not predict well for the group size of wild boar as compared with deer species, but the models were well fitted with the small and very small groups. Solitary individuals of wild boar avoided the predators during morning time. However, very small groups significantly preferred morning time and again avoided the presence of predators. Likewise, small groups preferred the plain areas and avoided human disturbances during morning time. Medium groups of wild boar avoided plain areas and human disturbances and preferred morning time, while the large groups avoided open areas and human disturbances (Table 3).
We modeled the binomial-dependent variable, i.e., group size of ungulates were classified as solitary, very small, small, medium, large and very large groups of ungulates, with the predictor variables, i.e., habitat (open and closed), topography (Pla, plane and gentle slope), distance to waterhole (DW), presence of predators (PP), time (AM and $\mathrm{PM}$ ), season (winter and summer) and human disturbance index (HDI). $R^{2}$ (Nagelkerke) is the coefficients of determination for logistic regression, AIC is the Akaike information criterion used to choose the best model (Burnham \& Anderson, 2002), Int, intercept and significance levels are indicated by $*(p<0.05), * *(p<0.001)$ and $* * *$ $(p<0.0001)$. Only the best model that was chosen by minimum AIC basis for each category of the group size of ungulates is included in the result (Burnham \& Anderson, 2002).

There were very few observations of gaur in our study area. The models were poorly fitted with the solitary and medium groups of gaur and marginally fitted for other group categories. Solitary individuals of gaur preferred closed habitats and predators but avoided plain areas and human disturbances. However, very small and small groups preferred plain areas and occurred less in the winter season and in presence of human disturbances. Likewise, medium groups of gaur preferred the plain areas during the summer season (Table 3). 
Table 3: Generalized linear models of the factors that influencing the grouping patterns of six ungulate species in the Chitwan National Park.

\begin{tabular}{|c|c|c|c|c|c|c|}
\hline Species & Group size & $\begin{array}{c}\text { Model terms and parameter } \\
\text { estimates (SE) }\end{array}$ & $\mathbf{R}^{2}$ & AIC & Wald & P-value \\
\hline \multirow[t]{6}{*}{ Chital } & solitary & $\begin{array}{l}1.54(0.50) \mathrm{Int}+0.024(0.002) \mathrm{DW}- \\
2.02(0.46) \mathrm{PP}^{* * *}\end{array}$ & 0.20 & 222.4 & 19.22 & $<0.0001$ \\
\hline & Very small & $\begin{array}{l}0.31(0.24)-0.004(0.002) \mathrm{DW}-1.65 \\
(0.32) \mathrm{PP} * * *\end{array}$ & 0.17 & 304.3 & 29.52 & $<0.0001$ \\
\hline & Small & $\begin{array}{l}1.63 \text { (0.45) Int+0.60 (0.31) Closed*_ } \\
0.43 \text { (0.30) Summer }\end{array}$ & 0.05 & 279.82 & 7.25 & 0.032 \\
\hline & Medium & $\begin{array}{l}0.94(0.22) \text { Int+0.29 }(0.21) \\
\text { Open+0.22 (0.25) Summer*-0.11 } \\
(0.09) \text { HDI* }^{*}\end{array}$ & 0.03 & 401.7 & 3.96 & 0.06 \\
\hline & Large & $\begin{array}{l}3.35(0.67)+1.27(0.54) \mathrm{Pla}^{*}+0.84 \\
(0.34) \mathrm{PP}^{*}-0.21(0.13) \mathrm{HDI}^{*}\end{array}$ & 0.10 & 252.7 & 14.94 & 0.002 \\
\hline & Very large & $\begin{array}{l}2.83(0.46) \text { Int }+0.55(0.27) \text { Open }+ \\
2.36(0.86) \mathrm{PP}^{* *}\end{array}$ & 0.19 & 146.2 & 11.09 & 0.002 \\
\hline \multirow[t]{2}{*}{ Sambar } & Solitary & $\begin{array}{l}1.41(0.9) \text { Int-1.56 (0.71) Open*-1.35 } \\
(0.56) \text { PP*-1.78 (0.61) Summer*-0.41 }^{*}{ }^{*}(0.2) \text { HDI }^{*}\end{array}$ & 0.44 & 99.03 & 16.13 & 0.002 \\
\hline & Very small & $\begin{array}{l}1.51(0.63) \text { Int+1.62 }(0.71) \\
\text { Open+1.51 (0.36) } \\
\text { PP**+1.63Summer**-0.38 } \\
(0.22) \text { HDI }^{*}\end{array}$ & 0.51 & 104.3 & 16.56 & 0.002 \\
\hline \multirow[t]{4}{*}{ Hog deer } & Solitary & 1.39 (0.64) Int+0.52 (0.75) Open & 0.02 & 62.7 & 1.2 & 0.07 \\
\hline & Very small & $0.41(0.52)$ Int-0.50 (0.63) Open & 0.02 & 72.0 & 0.89 & 0.09 \\
\hline & Small & $1.02(0.58)$ Int+0.01 (0.07) Open & 0.01 & 68.0 & 0.02 & 0.67 \\
\hline & Medium & $1.87(0.76)$ Int+0.56 (0.75) Open & 0.13 & 76.9 & 0.81 & 0.25 \\
\hline \multirow[t]{2}{*}{ Muntjac } & solitary & $\begin{array}{l}0.26(0.56) \mathrm{Int}+0.70(0.37) \mathrm{Open}^{*}{ }_{-} \\
1.01(0.39) \mathrm{PP}^{*}+1.27(0.4) \mathrm{AM}^{* *}\end{array}$ & 0.17 & 179.12 & 14.75 & 0.002 \\
\hline & Very small & $\begin{array}{l}0.26(0.37)-0.69(0.37) \\
\text { Open*+1.00(0.39) PP**-1.26 (0.39) } \\
\text { AM** }^{*}\end{array}$ & 0.16 & 179.13 & 14.76 & 0.002 \\
\hline \multirow[t]{5}{*}{ Wild boar } & Solitary & $\begin{array}{l}1.32(0.73) \text { Int-1.19 (0.81) PP-0.77 } \\
(0.67) \text { AM }\end{array}$ & 0.09 & 85.4 & 3.43 & 0.09 \\
\hline & Very small & $\begin{array}{l}1.52(0.40) \text { Int-0.52 (0.43) PP+0.89 } \\
(0.50) \mathrm{AM}^{*}\end{array}$ & 0.06 & 124.1 & 4.33 & 0.05 \\
\hline & small & $\begin{array}{l}1.24(0.62) \mathrm{Int}+0.48(0.29) \mathrm{Pla}-0.27 \\
(0.28) \mathrm{AM}-0.42(0.19) \text { HDI }\end{array}$ & 0.16 & 126.42 & 8.50 & 0.027 \\
\hline & Medium & $\begin{array}{l}0.66(0.24) \text { Int }-0.36(0.27) \mathrm{Pla}+0.15 \\
(0.28) \mathrm{AM}-0.22(0.17) \mathrm{HDI}\end{array}$ & 0.12 & 122.5 & 5.93 & 0.062 \\
\hline & Large & $\begin{array}{l}1.72(0.77) \text { Int }-5.38(0.001) \text { Open-0. } \\
25(0.02) \text { HDI }\end{array}$ & 0.11 & 55.55 & 0.75 & 0.21 \\
\hline \multirow[t]{4}{*}{ Gaur } & Solitary & $\begin{array}{l}224.92(0.00) \mathrm{Int}+198.89(0.00) \\
\text { Closed-87.14 (0.00) Pla+21.43 } \\
(0.00) \text { PP-7.49 (0.00) HDI } \\
\end{array}$ & 0.59 & 36.2 & 0.001 & 0.98 \\
\hline & Very small & $\begin{array}{l}0.71(0.66) \text { Int+1.45 (1.13) Pla-1.78 } \\
(1.09) \text { Winter*-0.19 (0.28) HDI }\end{array}$ & 0.24 & 41.8 & 4.35 & 0.05 \\
\hline & Small & $\begin{array}{l}0.061(0.66) \mathrm{Int}+1.35(1.08) \mathrm{Pla}-1.95 \\
(1.10) \text { Winter**-0.24(0.22) HDI }\end{array}$ & 0.25 & 46.8 & 4.35 & 0.05 \\
\hline & Medium & $\begin{array}{l}3.83 \text { (2.78) Int+1.16 (1.35) Pla+0.11 } \\
(0.98) \text { Summer }\end{array}$ & 0.05 & 27.3 & 0.83 & 0.56 \\
\hline
\end{tabular}




\section{Population composition}

We found a higher contribution of female individuals for the formation of the larger groups in all the species, and these larger groups possess the greater number of subadult and young individuals. There were no solitary subadults and young in these ungulate species except muntjac in which we found just two subadults as solitary (Fig. 3). We performed the two-way ANOVA and it showed that there were significant contributions of age and sexes of ungulates $(p<0.05)$ except muntjac $(p=$ $0.11)$ and sambar $(p=0.17)$ on the formation of different sizes of groups.

Sex ratio was biased towards females for all species (Table 4). The male to female ratio was the highest in sambar deer and the least in wild boar, while the young to female ratio was the lowest in gaur and the highest in wild boar (Table 4). The ratio of numbers of young to those of adult individuals $\left(R^{2}\right.$ $=0.04)$ and the sex ratio of ungulates $\left(R^{2}=0.40\right)$ were not significantly $(p>0.05)$ dependent on their density (Figure 4). We also found a greater number of male, female, subadult and young in the summer season for all species except gaur (Table 4). We performed a two-way ANOVA to test the differences in the age and sex ratio of ungulates across two seasons. There were significant differences within the age and sexes for chital $(F=$ 23.3, $P=0.01)$, sambar $(F=10.7, P=0.04)$, hog deer $(F=19.2, P=0.01)$, muntjac $(F=8.7, P=$ $0.05)$, wild boar $(F=25.9, P=0.01)$ and not significant for gaur $(F=3.4, P>0.05)$. However, there were significant differences in the age and sexes among the seasons for hog deer $(F=8.84, P$ $=0.05)$ and wild boar $(F=30.5, P=0.01)$ while others were not significant $(P>0.05)$.

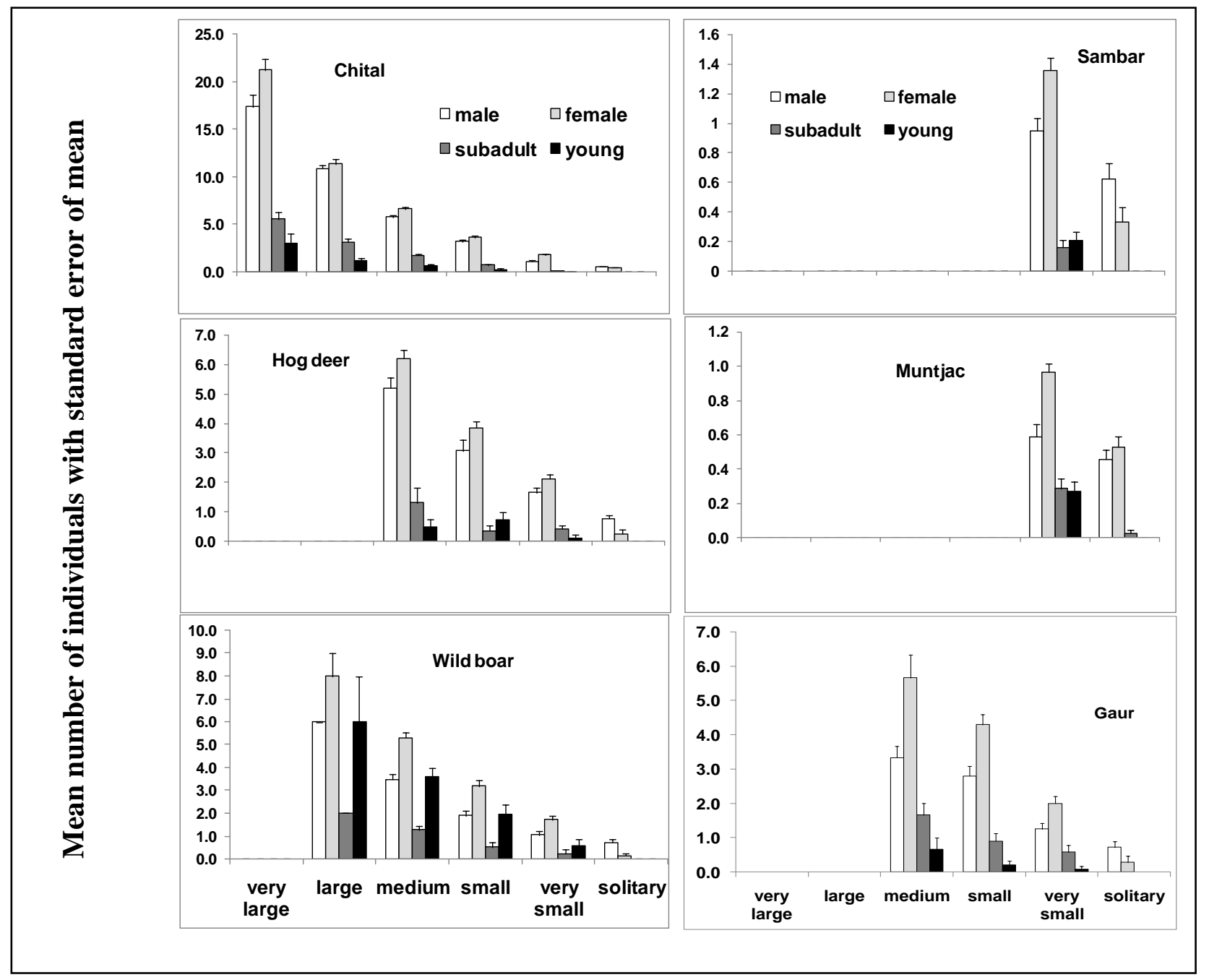

Fig. 3. Contribution of age and sex (mean and standard error of mean) for the formation of different sizes of the groups (very large, large, medium, small, very small and solitary). 
Table 4: Age and sex composition of wild ungulates in the CNP.

\begin{tabular}{|l|l|l|l|l|l|l|l|l|}
\hline \multirow{3}{*}{ Animal type } & \multicolumn{9}{|c|}{ Age and sex composition (\%) } \\
\cline { 2 - 10 } & \multicolumn{3}{|c}{ Male } & \multicolumn{2}{c|}{ Female } & \multicolumn{2}{c|}{ Sub-adult } & \multicolumn{2}{c|}{ Young } \\
\cline { 2 - 10 } & Winter & Summer & Winter & Summer & Winter & Summer & Winter & Summer \\
\hline Chital & 15.15 & 24.39 & 18.73 & 26.40 & 4.71 & 6.33 & 1.70 & 2.59 \\
\hline Sambar & 17.46 & 21.69 & 15.34 & 33.33 & 0.53 & 4.76 & 1.06 & 5.82 \\
\hline Hog deer & 14.89 & 25.23 & 17.33 & 29.79 & 1.22 & 6.38 & 1.82 & 3.34 \\
\hline Muntjac & 15.92 & 18.91 & 15.42 & 32.84 & 1.99 & 6.97 & 1.99 & 5.97 \\
\hline Wild boar & 9.84 & 16.94 & 15.30 & 24.86 & 2.32 & 5.87 & 8.33 & 16.53 \\
\hline Gaur & 25.37 & 8.24 & 37.03 & 13.52 & 6.47 & 5.87 & 2.35 & 1.15 \\
\hline
\end{tabular}

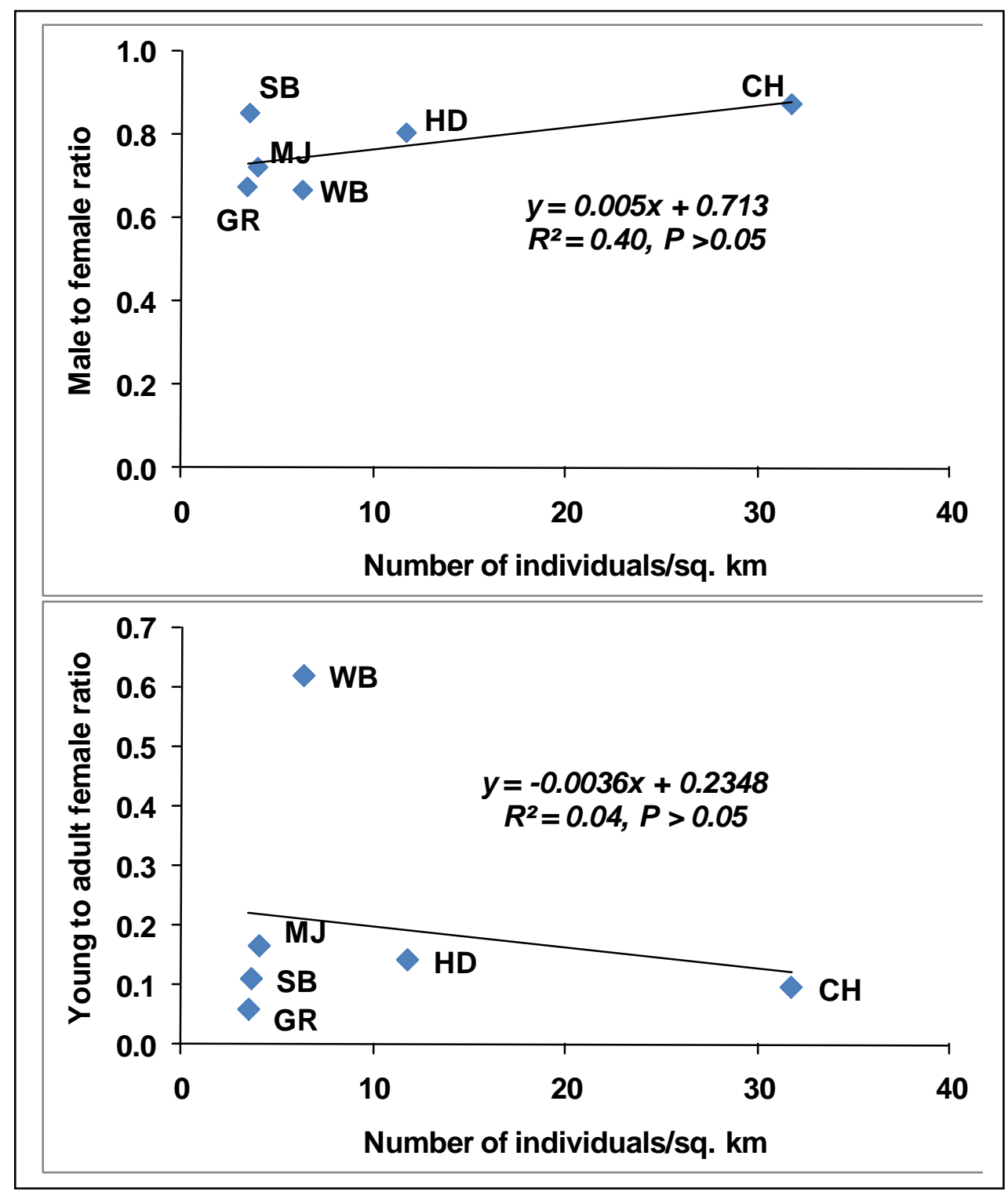

Fig. 4. Relationship between population density and sex ratio of ungulates.CH, chital, HD, hog deer, SB, sambar, MJ, muntjac, WB, wild boar, GR, gaur. 


\section{DISCUSSION}

\section{Social organization}

Chital was often found to be gregarious (Seidensticker, 1976; Dinerstein, 1980; Barrette, 1991; Karanth \& Sunquist, 1992; Khan et al., 1995), but in our study, the mean group size and the range of observed group sizes were higher than in other (Khan et al., 1995) (Table 1). Large and very large groups of chital were recorded in the open areas such as grasslands while medium-sized groups were mainly found in closed habitats (Table 3 ), which was mainly due to human disturbances and presence of predators. Similarly, average group size of chital was found to be higher in winter compared to summer season. However, the number of individuals of chital was higher in summer $(n=$ 2280) than winter $(n=1541)$. During winter, larger groups of this gregarious species mainly recorded in the open areas like grasslands for grazing and taking sunbath. In the summer season, they were widely distributed in medium and small sized groups in most parts of the habitats of the study area where they got enough food (Raman, 1997). Sambar is mainly reported to occur in very small groups (Karanth \& Sunquist, 1992; Khan et al., 1995) and we mostly found solitary individuals. The larger groups of sambar were recorded during summer season. We never found sambar deer forming groups of more than 5 individuals, and very small-sized groups characterized its social organization in the whole CNP, whereas it forms larger groups in more open areas, such as grassy savannas (Bagchi et al., 2003).

Muntjac is also known to occur in small groups (Dinerstein, 1980, Khan et al., 1995), with males usually being solitary or in small groups and females forming small groups with fawn and subadults. Social organization of muntjac was observed to be largely asocial and less living in small groups. Solitary animals, pairs and family units were the characteristic of this species, as observed by Rahmani (1990). There was very less effect of season on forming group size of muntjac. Hog deer mainly occurred in solitary to medium groups with the range of group size varied from 1 to 17 and larger groups were observed during summer season. However, Schaller (1967) observed a group of 40 individuals of hog deer in India. Likewise, Dhungel and O'Gara (1991) found the range of group size from one to twenty individuals in the CNP. The larger groups of hog deer mainly found during fawning season. Such variation in the group size of hog deer in this park was mainly due to the trend of the rapid increase of the height and density of tall grasses that depends on temperature and rainfall (Dhungel \& O'Gara, 1991).

There is very little information available on social organization of gaur. However, in summer season, we found gaur in larger groups as compared with winter season (Table 1 and 2). Larger groups exceeding 10 individuals were very rare in gaur, because most of the adult males were solitary, and usually they join the larger groups during mating periods. The grouping patterns in wild boar depended on the periods of a year and the contributions of young individuals to form a group. After the burning of grasslands and forests (February - June), there was greater availability of new shoots and tubers of plants, which provides the higher amount of food for wild boar. As a result we found more number of young individuals of the wild boar in this period, which attributed to the larger groups.

Solitary individuals of ungulates were more common during winter, which was due to less forage availability in the dry winter season. At the end of winter, when plenty of forage is available, the solitary individuals again joined the groups, which contributed to the larger number of groups during the summer. Stags of deer could have contributed to this by forming bachelor groups after shedding their antlers. This could have also been due to temporary feeding aggregations (Mishra, 1982; Raman, 1997). In the most of the ungulate species, adult males form the greatest proportion of the solitary individuals, because they are less vulnerable to predation by tigers and leopards.

\section{Factors affecting the social organization}

We found that human disturbances, predators and open habitats were the most important predictors of the social organization of these six species of ungulates (Bhattarai \& Kindlmann, 2012, 2013). There were low effects of topography, time and season on the grouping patterns. The waterholes or wetlands are important habitats for ungulates, but this did not affect significantly the grouping patterns. The detection probability of ungulates nearby the waterholes was much higher than far from the waterholes and the detections declined with the increased distance from the waterhole (Figure 2). All the species showed a negative relation with human disturbance, which can be taken as a serious threat to these ungulates in this region. Such disturbances break the larger groups into smaller ones, which increase the likelihood of being attacked by the predators and reduce the 
chance of sexual selection. This can have detrimental effects on the population dynamics of these ungulate species (Karanth \& Sunquist, 1992).

The larger groups of chital in the rich areas of predators showed that living in a group is an antipredatory strategy, as smaller groups are less likely to be encountered by an ambush predator like tiger in the dense forests, whilst in the open habitats, animals resorted to safety in large numbers (Raman, 1997). The female individuals with fawns and subadults preferred to stay inside forests, which provided them protection, rather than in open habitats. Solitary individuals of sambar deer avoided open areas but preferred forests, which can increase the risk of predation, as sambar deer forms a preferred diet of the tiger in this region (Bhattarai \& Kindlmann, 2012). However, the effect of other constraints, such as forage quality and abundance cannot be completely ruled out. Hog deer preferred open habitats like tall grassland and floodplain areas (Dhungel \& O'Gara, 1991). In the CNP, floodplains are the major hotspots for livestock grazing (pers. obs.) and it has been a serious challenge to protect this species here. We cannot perfectly say the factors influencing the grouping patterns in gaur, because gaur is very rare in the $\mathrm{CNP}$, and we have a very low number of samples for this. However, our results predicted that grouping patterns in gaur was mainly affected by the closed habitats and the human disturbances. We observed gaur very far from the human settlements. The earlier studies of Bongers et al. (2009) and Markovchick-Nicholls et al. (2008) reported that many species are tolerant of moderate human disturbances but large bodied species like gaur and sambar deer in our case are more vulnerable to the disturbances (Tania et al., 2009).

\section{Population composition}

For all the species of ungulates, the adult sex ratio was skewed towards females. It is a common phenomenon in cervids (Khan et al., 1995) and is often interpreted in terms of sexual selection (Clutton- Brock et al., 1982). We cannot judge the sex ratio in gaur, because small sample size (only 32 groups). The young and female composition was lower in deer and gaur as compared to the study of Karanth and Sunquist (1992), which might be due to environmental stochasticity, which plays an important role in shaping demographic processes in herbivores. Also the important habitats of the CNP located in the lowland areas are heavily used by the local inhabitants, which put continuous pressure in this area. Low population density with very few numbers of young is not a viable population. This indicates that if these small populations persist, they will rapidly lose genetic variability due to inbreeding depression (Bhowmik \& Chakraborty, 2001). Likewise, annual floods in the rivers are also the major factors that determine the demographic structures of ungulates, e.g., hog deer, which inhabits and prefers flood plain areas, and possesses a serious threat from the floods. There were records of more than 100 in 1990, 200 in 1993 and 240 in 2002 of ungulates killed by the floods in and around the CNP (Bhattarai, 2003). The special behavioral and morphological characteristics of the hog deer are closely linked with tall grass and floodplain areas (Schaller, 1967) that are lost annually by annual floods. Hog deer seems to be vulnerable due to such floods however in return such annual floods create new grasslands which are the most favorite habitat for this deer.

\section{CONCLUSION}

These results indicate that population structures in ungulates are influenced by the habitats, predators and human disturbances. In the disturbed areas, ungulates resorted into small groups in the forest areas, which might be a mechanism of escaping and hiding from human disturbances. These species form large groups in the open areas and small groups in forests, which were less disturbed by humans and where predators were more abundant. Age-sex structures of ungulates implied that there was bias towards the females and these species possess fewer numbers of young individuals, except of wild boar. For long term conservation and to achieve a balanced population of ungulates, there should be a continuous monitoring in order to perceive changes in the demography of a population over time. Regular monitoring of the population of these major prey species of the tiger is important by adopting rapid assessment techniques to achieve this information and facilitate expedient planning.

\section{ACKNOWLEDGEMENTS}

We are grateful to the Department of National Parks and Wildlife Conservation for the permission to work in the Chitwan National Park. This research was supported by the grant LC06073 of the Czech Ministry of Education and by CzechGlobe - Global Change Research Institute, ASCR, Czech Republic. We are also thankful to the friends who helped us during data collection. 


\section{REFERENCES}

Bagchi, S.; Goyal, S. P. and Sankar, K. (2003). Niche relationships of an ungulate assemblage in a dry tropical forest. Journal of Mammalogy, 84: 981-988.

Bagchi, S.; Goyal, S. P. and Sankar, K. (2004). Herbivore density and biomass in a semi-arid tropical dry deciduous forest of western India. Journal of Tropical Ecology 20: 475-478.

Barrette, C. (1991). The size of Axis deer fluid groups in Wilpattu National Park, Sri Lanka. Mammalia, 55: 207-220.

Bhattarai B. P. and Kindlmann P. (2013). Effect of human disturbance on the prey of tiger in the Chitwan National Park - Implications for park management. Journal of Environmental Management, 131: 343-350.

Bhattarai, B. P. (2003). Population status and conservation threats on wild ungulates of Barandabhar Corridor Forest, Chitwan, Nepal. Dissertation. Tribhuvan University, Kathmandu, Nepal.

Bhattarai, B. P. and Kindlmann, P. (2012). Interactions between Bengal tiger (Panthera tigris) and leopard (Panthera pardus): implications for their conservation. Biodiversity and Conservation, 21: 20752094.

Bhowmik, M. K. and Chakraborty, T. (2001). Density of $\mathrm{Hog}$ deer in Jaldapara and Gorumara protected areas of Himalayan West Bengal. Tiger Paper, 28: 8-18.

Bongers, F., Poorter, L., Hawthorne, W. D. and Sheil, D. (2009). The intermediate disturbance hypothesis applies to tropical forests, but disturbance contributes little to tree diversity. Ecology Letters, 12: 1-8.

Buckland, S. T.; Anderson, D. R.; Burnham, K. P.; Laake, J. L.; Borchers, D. L. and Thomas, L. (2004). Introduction to Distance Sampling: Estimating Abundance of Biological Populations. Oxford University Press, Oxford, pp. 432.

Caughley, G. (1977). Analysis of vertebrate populations. John Wiley and Sons, New York. pp. 234.

Champion, F. W. and Seth, S. K. (1968). A revised survey of the forest types of India. Manager, Government of India Press, Nasik, India. pp. 404.

Clutton-Brock, T. H.; Guinness, F. E. and Albon, S. D. (1982). Red deer: behaviour and ecology of two sexes. Edinburgh University Press, Edinburgh. pp. 400.

CNP (2017). Chitwan National Park: a fact sheet. http://www.chitwannationalpark.gov.np/inde x.php/biodiversity

Dhungel, S. K. and O'Gara, B.W. (1991). Ecology of the hog deer in Royal Chitwan National Park, Nepal. Wildlife Monograph No. 119. Wildlife Society, Bethesda, MD.

Dinerstein, E. (1980). An ecological survey of the Royal Karnali- Bardia Wildlife Reserve, Nepal, part 3: ungulate populations. Biological Conservation, 18: 5-38.

Eisenberg, J. F. and Seidensticker, J. (1976). Ungulates in southern Asia: a consideration of biomass estimates for selected habitats. Biological Conservation, 10: 293-308.

Fritz, H. and Garine-Wichatitsky, M. de. (1996). Foraging in a social antelope: effects of groups size on foraging and resource perception in impala. Journal of Animal Ecology, 65: 736-742.

Geraldeau, L. A. (1988). The stable group and the determinants of foraging group size. In: (C.N. Slobodchikoff, ed) The ecology of social behavior. Academic Press, San Diego, CA. pp. 33-53.

Jarman, P. J. (1997). The social organization of antelope in relation to their ecology. Behaviour, 48: 215-267.

Johnsingh, A. J.T. and Sankar, K. (1991). Food plants of chital, sambar and cattle on Mundanthurai plateau, Tamil Nadu, South India. Mammalia, 55: 57-66.

Karanth, K. U. and Stith, B. M. (1999). Prey depletion as a critical determinant of tiger population viability. In: Seidensticker J, Christie $\mathrm{S}$ and Jackson $\mathrm{P}$ (Ed) Riding the tiger: tiger conservation in humandominated landscapes.Cambridge University Press, Cambridge, United Kingdom, pp. 100-113.

Karanth, K. U. and Sunquist, M. E. (1992). Population structure, density and biomass of large herbivores in the tropical forests of Nagarhole, India. Journal of Tropical Ecology, 8: 21-35.

Khan, J. A., Chellam R. and Johnsingh, A. J. T. (1995). Group size and age-sex composition of three major ungulate species in Gir lion sanctuary, Gujarat, India. Journal of Bombay Natural History Society, 92: 295-302. 
Khan, J. A., Chellam, R., Rodgers W. A. and Johnsingh A. J. T. (1996). Ungulate densities and biomass in the tropical dry deciduous forests of Gir, Gujarat, India. Journal of Tropical Ecology, 12: 149-162.

Leuthold, W. (1977). African ungulates: a comparative review of their ethology and behavioural ecology. Springer-Verlag, Berlin. pp. 307.

Markovchick-Nicholls, L.; Regan, H. M.; Deutschman, D. H.; Widyanata, A.; Martin, B.; Noreke, L et al. (2008). Relationships between human disturbance and wildlife land use in urban habitat fragments. Conservation Biology, 22: 99-109.

Mishra, H. R. (1982). The ecology and behaviour of chital (Axis axis) in the Royal Chitwan National Park, Nepal. Dissertation, University of Edinburgh.

Prater, S. H. (1971). The book of Indian animals. Bombay Natural History Society, Bombay. pp. 332.

Rahmani, A. R. (1990). Distribution, density, group size and conservation of the Indian gazelle or chinkara Gazella bennetti (Sykes 1831) in Rajasthan, India. Biological Conservation, 51: $177-189$.

Raman, T. R. S. (1997). Factors influencing seasonal and monthly changes in the group size of chital or axis deer in southern India. Journal of Bioscience, 22: 203-218.
Schaller, G. B. (1967). The deer and the tiger: a study of wildlife in India. Chicago University Press, Chicago, IL. pp. 384.

Seidensticker, J. (1976). Ungulate populations in Chitwan Valley, Nepal. Biological Conservation, 10: 183-210.

Smith, J. L. D.; Ahearn, S. C. and McDougal, C. (1998). Landscape analysis of tiger distribution and habitat quality in Nepal. Conservation Biology, 12: 1338-1346.

Stoen, O. G. and Wegge, P. (1996). Prey selection and prey removal by tiger (Panthera tigris) during the dry season in lowland Nepal. Mammalia, 60: 363-373.

Tania, U. H.; Peres, C. A. and Dolman, P. M. (2009). Regional scale effects of human density and forest disturbance on large-bodied vertebrates throughout the Yucatán Peninsula, Mexico. Biological Conservation, 142: 134-148.

Underwood, R. (1982). Seasonal changes in African ungulate groups. Journal of Zoology, 196: 191-205.

Wikramanayake, E. D.; Dinerstein, E.; Loucks, C.; Olson, D.; Morrison, J.; Lamoreux, J. et al. (2001). Terrestrial ecoregions of the IndoPacific: a conservation assessment. Island Press: Washington, D. C. 